\title{
Using a Global Systematic Framework Tool to Identify Pharmacy Workforce Development Needs: A National Case Study on Saudi Arabia
}

\author{
Dalia Almaghaslah (D) \\ Abdulrhman Alsayari (D) ${ }^{2}$ \\ 'Department of Clinical Pharmacy, King \\ Khalid University, Abha, Saudi Arabia; \\ ${ }^{2}$ Department of Pharmacognosy, King \\ Khalid University, Abha, Saudi Arabia
}

Background: Healthcare is one of the key focuses of the Saudi Vision 2030. Identifying and acknowledging the strengths and weakness of the healthcare manpower, including pharmacy, are crucial for workforce development and for achievement of the vision.

Methods: This paper used a global systematic framework tool, the International Pharmaceutical Federation the International 21 Development Goals (FIP DGs), as a roadmap to identify pharmacy workforce development needs.

Results: An increase in the number of qualified Saudi pharmacy employees was successfully achieved by increasing the number of pharmacy education institutions. Several postgraduate pharmacy programs (Master's and Ph.D.) were also established. Some pharmacy colleges around the country obtained national and international accreditation/certification from reputable quality assurance organizations, such as the NAAA, ACPE and CCAPP. Clinical pharmacy residency programs were expanded to cover various specialties. No comprehensive competency framework exists for pharmacists in Saudi Arabia. A wide range of CDP programs, including electronic courses, have been offered for healthcare practitioners and accredited by SCFHS. While a certain number of CME hours are required for re-registration as a pharmacist, these CME hours are currently not linked to a needs-based health initiative. Several initiatives and strategies have been developed and implemented to address pharmaceutical workforce gender and diversity balances. The pharmacy profession is regulated by the MOH, the SCFHS, and the HRSD.

Discussion and Conclusion: Among the three clusters of the DGs - Academia, Professional Development, and Systems - Cluster 2, Professional Development, was identified as a priority area for improvement. Within this cluster, these particular DGs were selected as top priority: competency development (DG 5), leadership development (DG 6), and working with others (DG 8). Two DGs in Cluster 3, Systems, were also highlighted as priorities: continuing professional development strategies (DG 9) and impact and outcome (DG 11).

Keywords: pharmacy workforce, Saudi Arabia, FIP development goals

\section{Introduction}

The Saudi Arabian healthcare system consists of two major divisions: government and private. The government division includes the Ministry of Health centers and other bodies. Healthcare is delivered at three categories: primary, through primary healthcare centers; secondary, through government hospitals; and tertiary care through general or specialized hospitals. The private sector provides all the three,
Correspondence: Dalia Almaghaslah College of Pharmacy, King Khalid University, PO Box 1882, Abha, 6144I, Saudi Arabia

Email damoazle@kku.edu.sa 
along with community pharmacies. Pharmacists may be employed in government health institutions, ie, hospitals and primary healthcare centers, and private healthcare, community pharmacies, academia, the pharmaceutical industry, and other and agencies, such as regulatory authorities. ${ }^{1}$ The Saudi 2030 Vision's strategic goals involve ensuring equitable access to healthcare for both citizens and residents of the Kingdom. This requires improving the value of health services through increasing the quality of services provided and focusing on preventive and primary healthcare, while maintaining therapeutic care. These goals are to be achieved through the implementation of the suggested health transition programs:

the corporatization of a health care model, a health insurance program and the purchase of health services, a private sector participation program, governance, e-health, and the workforce. ${ }^{2}$

Hence, health workforce data is an essential factor for monitoring and planning the transformative changes outlined in the 2030 Saudi vision. The pharmacy profession has witnessed drastic changes regarding the practice of this career. The transition of the pharmacist's traditional roles, such as dispensing and compounding medications, to more advanced pharmaceutical care roles, necessitate a transition in pharmacy education, as well as continuous professional development (CPD). ${ }^{3}$ The availability of sufficient numbers of pharmacy employees with the required skills and competencies is important for achieving the nation's positive health outcomes. Paying more attention to pharmacy workforce development would enhance healthcare provision in particular pharmaceutical primary healthcare provision. The pharmacy regulatory bodies in Saudi Arabia, the Ministry of Health (MOH), the Saudi Commission for Health Specialties (SCFHS), and the Ministry of Labor and Social Development (HRSD) have responded to the challenges that affect the pharmacy profession by issuing several rules and regulations. ${ }^{1}$ One of the major previous challenges was limited jobs in the government division, which required the support of the largest employment sector, community pharmacy, to provide employment for local pharmacists (currently only $4.2 \%$ are Saudi). During the past few decades, the country strongly relied on non-national pharmacists due to the limited number of pharmacy schools in the country. As the number of pharmacy schools increased, the number of pharmacy graduates increased. Hence, most of the jobs in the public sector (preferred sector) were nationalised
(Saudised), ie, non-national pharmacists were replaced by national (Saudi) pharmacists. However, the private sector was still mainly run by non-national staff. ${ }^{1}$ Unequal gender distribution is also a major defect in the private sector, with only $4.6 \%$ of the total pharmacists being women. Additionally, the proportion of female student pharmacists is slightly higher $(54.3 \%)$ than male student pharmacists, but they comprise only $12.8 \%$ of the workforce. ${ }^{1}$ In other words, the number of females studying pharmacy is higher than males, but they have limited employment opportunities compared to male pharmacists, especially in the community pharmacy sector. Recently issued regulations will ease the restrictions that previously controlled the employment of female pharmacists in community pharmacies and will gradually nationalise (Saudising) the profession in two stages: $20 \%$ by 2020 and $30 \%$ by 2021 . A national assessment of the pharmacy workforce is not available; hence, the aim of the study was to describe the current status of pharmacy workforce, as well as to identify pharmacy workforce needs using the International Pharmaceutical Federation (FIP) Development Goals (DGs) Workforce element as a global systematic tool. ${ }^{4,5}$

\section{Methodology}

This study was conducted in two stages. First, a needs-based assessment of the current workforce and services provision was completed. Second, the results were assessed against the FIP DGs Workforce element. The needs assessment process was carried out through the collection of workforce data from a variety of sources, including pharmacy regulatory authorities, such as the MOH Health Statistics Yearbook (2018), SCFHS reports and website, as well as published journal articles. ${ }^{6,7}$ Data pertaining to pharmacy education and quality assurance of education was collected from the Ministry of Education websites and the National Center for Academic Accreditation and Evaluation (NCAAA), as well as published literature. The identified workforce status, ie, projects and challenges, was then mapped to the FIP DGs Workforce element. Based on previous studies assessing workforce status in other countries ${ }^{3,8}$ prioritisation of the needs or analysis of the gaps was conducted by categorising DGs into failed to meet, partially met, and met. The initial categorization was conducted by the study authors based on relevant workforce data. Validating the initial categorization was achieved by conducting a consensus panel involving pharmacists working in different pharmacy sectors ie, 2 hospital pharmacists, 2 community pharmacists, 2 pharmacists working in regulatory positions, and 2 working in 
academia to categorize DGs following the same process in the first categorization stage. The final categorization was achieved based on their feedback, refer to Table 1. The original 13 DGs are grouped in three clusters: Academic (3 DGs), Professional Development (5 DGs) and Systems (5 DGs). Each cluster was categorized into failed to meet, partially met and met.

\section{Results}

Needs-based assessment of pharmacy workforce and service provision

\section{Cluster I: Academic \\ DG I- Academic Capacity}

The supply side of the workforce is supported through engagement with higher education policy makers in both pharmaceutical sciences education and clinical practice. The number of pharmacy schools in the country rose to 30 , of which 7 are private. The pharmacy colleges are distributed throughout the different regions of the Kingdom, with an average class size of $70 .{ }^{9}$ Two colleges are male only and one is female only. According to the most recent SCFHS report in 2016, and based on their recommendation to avoid an oversupply of pharmacists, the number of colleges has been held at the current level. ${ }^{1}$ Presently, the pharmacy programs offer two entry level pharmacy degrees: Doctor of Pharmacy (PharmD) and Bachelor of Pharmacy (B. Pharm) ${ }^{10,11}$ Some colleges offer both programs to undergraduate pharmacy students, but the Pharm D program is gaining popularity. The latest SCFHS report indicates that the current number of student pharmacists enrolled in undergraduate programs has stayed approximately the same, 14,395, of which 391 are studying abroad. ${ }^{7}$ Clinical pharmacy education in Saudi Arabia is still facing some challenges that are similar to those in the rest of the world. These difficulties include the limited numbers of qualified clinical staff and preceptors to supervise students during the Introductory Pharmacy Practice Experiences (IPPE), as well as the Advanced Pharmacy Practice Experiences (APPE). ${ }^{12,13}$ Another issue is the limited training sites in hospitals and the unstandardized clinical pharmacy training program for the increasing numbers of Pharm D students. It has been difficult to fill these training positions, especially at the universities that are not affiliated with a teaching hospital. ${ }^{10,14}$ The limited use of active learning strategies, self-directed education and technology in the pharmacy curricula has also negatively affected clinical pharmacy education. ${ }^{1}$

\section{DG 2- Early Career Training Strategy}

There are several foundational training infrastructures available for newly registered pharmacy workforce. Postgraduate academic pharmacy programs, ie, Master of Science (MSc) and Doctor of Philosophy (PhD), are offered by a few pharmacy colleges in Saudi Arabia and distributed as follows: King Saud University has $6 \mathrm{MSc}$ programs and $4 \mathrm{PhD}$ programs, King Abdulaziz University has $4 \mathrm{MSc}$ programs, Umm al-Qura has 3 MSc programs, Prince Sattam bin Abdulaziz University has two MSc programs, and King Faisal University, Qassim University, and Jazan University have one MSc program each. ${ }^{15-21}$ The SCFHS offers a 2-year Diploma Certificate in General Clinical Pharmacy that is equivalent to a professional Master's degree and prepare the graduate to be registered as a pharmacist one (senior Pharmacist) after meeting the other requirements. A 3-year Saudi Certificate in Clinical Pharmacy is equivalent to a professional Doctorate degree and prepare the pharmacist to be registered as a consultant pharmacist after meeting the other requirements. ${ }^{22}$ Currently, 20 healthcare centers are accredited by the SCFHS to provide residency programs in clinical pharmacy. In addition, King Saud University Medical City (KSUMC), in conjunction with King Saud University College of Pharmacy, was approved as a site to offer the Ambulatory Care Pharmacy Residency Program (R3). ${ }^{7}$ Pharmacists can be classified as either pharmacist, pharmacist 1 (senior pharmacist) or consultant pharmacist. Licensing as a pharmacist requires a Bachelor's degree in pharmacy or Doctorate of Pharmacy or an equivalent. Licensing as a pharmacist one requires a postgraduate degree (eg, Master's degree in pharmacy), Pharmacy Residency Program (PGY1 or PGY2) or other degree recognized by the SCFHS, as well as fulfilment of all the other requirements. ${ }^{23}$ Licensing as a consultant pharmacist requires the Saudi Certificate in Clinical Pharmacy or equivalent (eg, Philosophy degree in pharmacy field/ specialty), along with fulfilment of all the other requirements. ${ }^{9}$ According to the SCFHS latest report, 81 pharmacists were enrolled in clinical pharmacy residency programs. A total of 262 were enrolled in postgraduate pharmacy programs, ie, M.Sc. and Doctor of Philosophy (Ph.D.), in King Saud University and King Abdulaziz University. The number of student pharmacists enrolled in postgraduate pharmacy programs or their equivalent outside the country is currently $453 .^{7}$ 


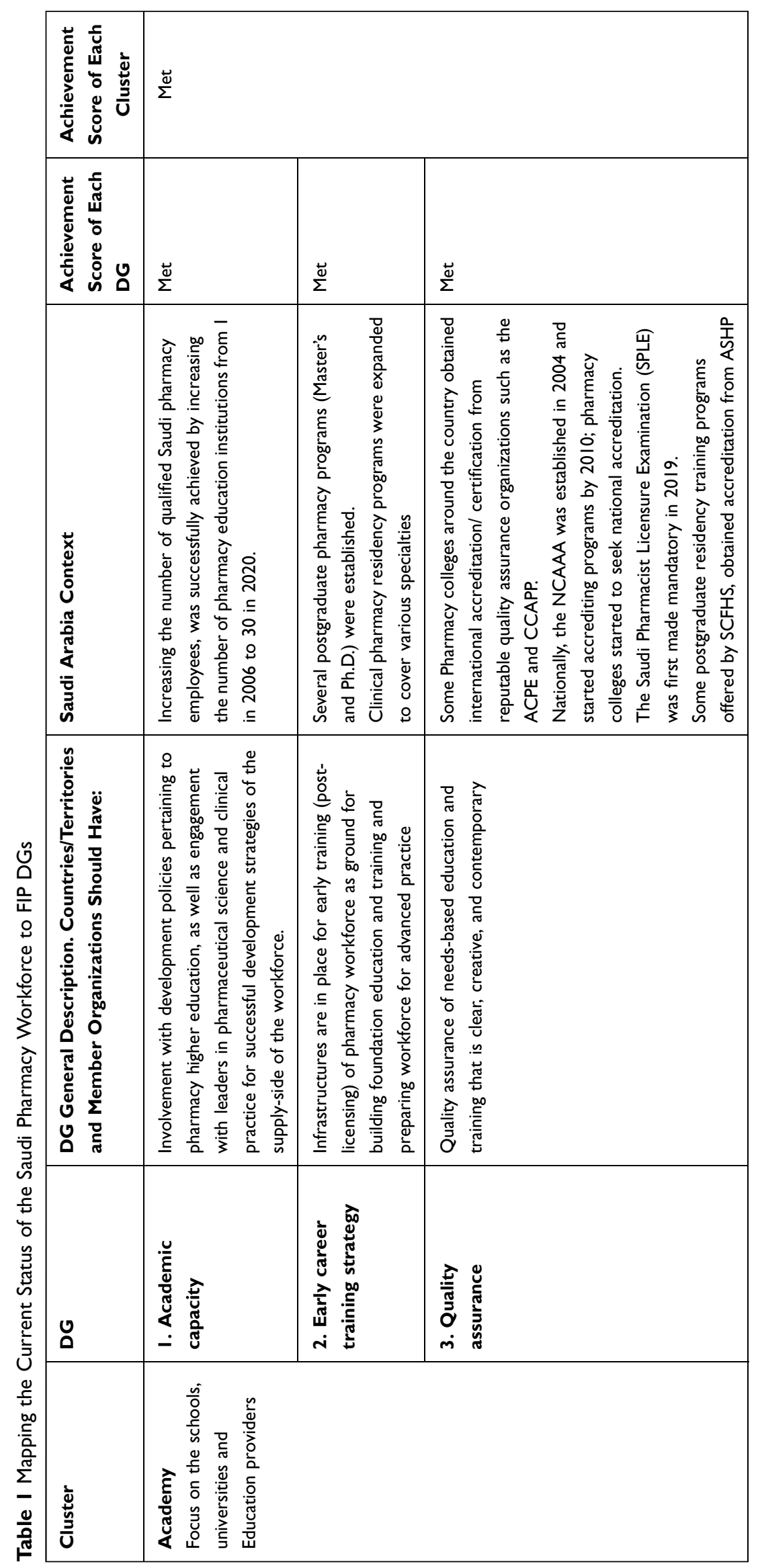




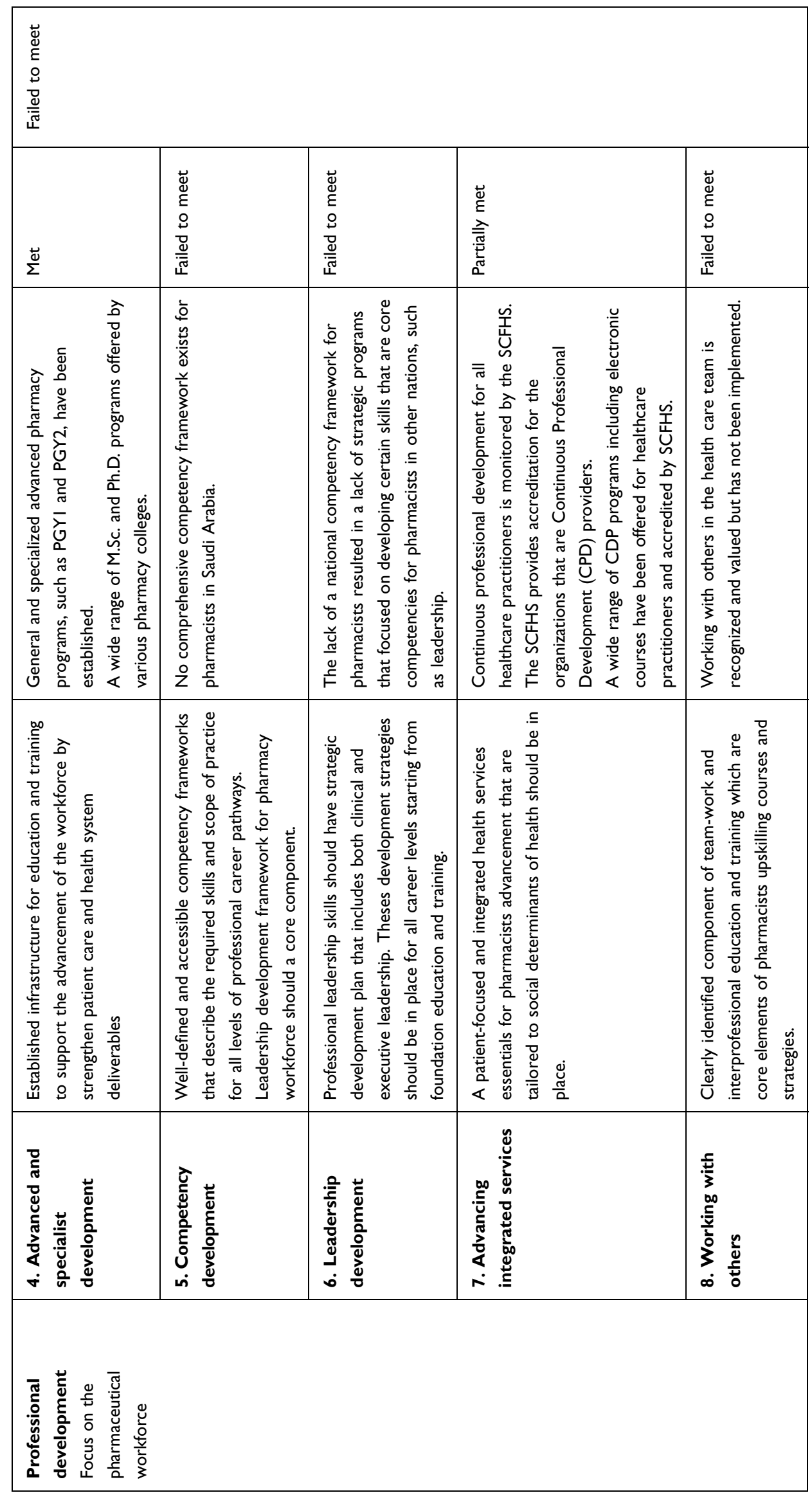




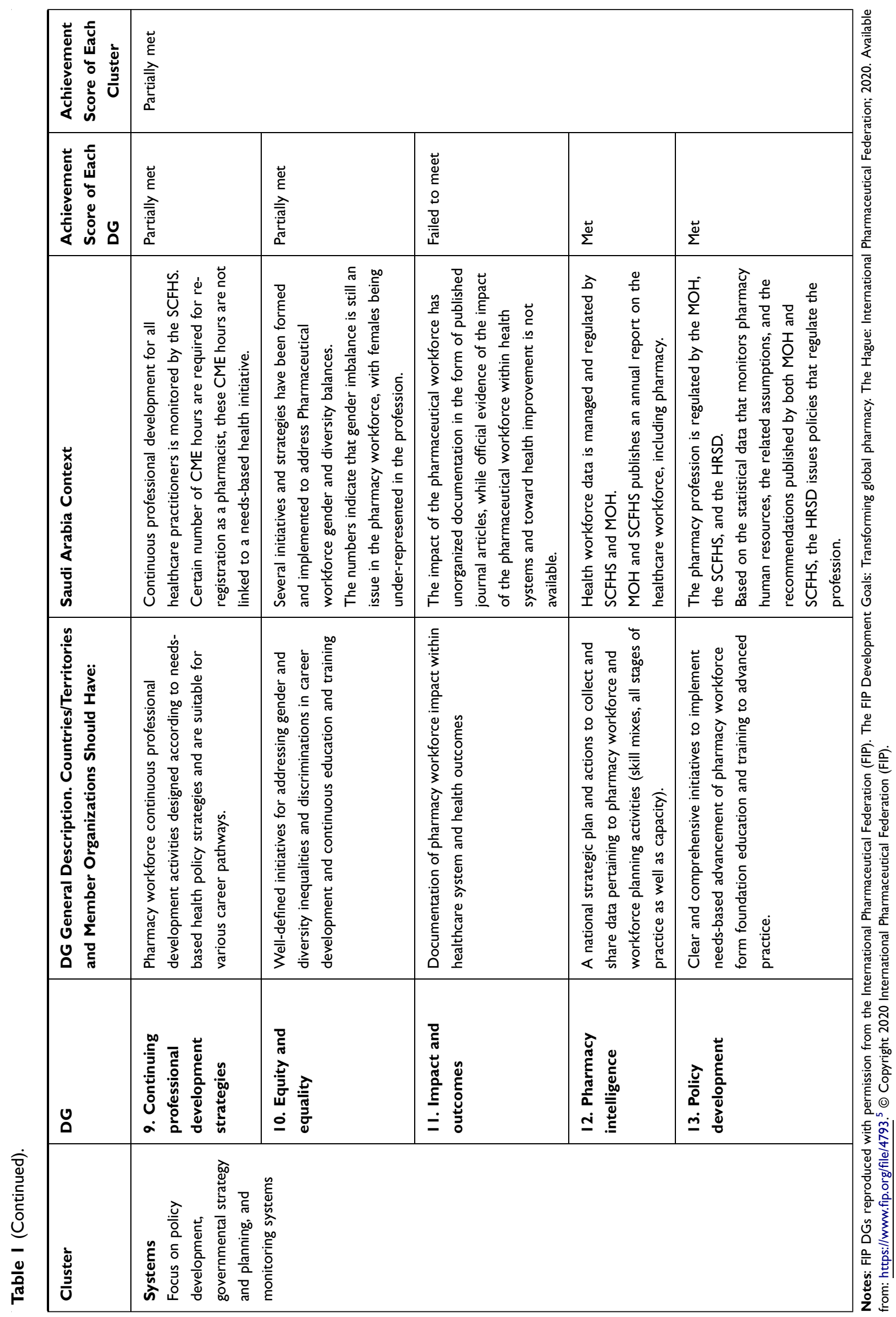




\section{DG 3- Quality Assurance}

Quality assurance strategies of needs-based education and training that are clear, contemporary and creative are in place. Regarding pharmacy education quality assurance, some colleges have obtained international certification/ accreditation of their programs. The Accreditation Council for Pharmacy Education (ACPE) has certified four undergraduate pharmacy programs, ie, Bachelor of Pharmacy and Pharm D, that are delivered by King Saud University, as well as the Doctor of Pharmacy (PharmD) programs of Qassim University College of Pharmacy, King Faisal University College of Clinical Pharmacy, Prince Sattam bin Abdulaziz University College of Pharmacy (Bachelor of Pharmaceutical Sciences (BPS), and Batterjee Medical College Pharmacy Program (PharmD). ${ }^{24}$ Additional accreditations have been given to the following programs by the associations mentioned. The Canadian Council for Accreditation of Pharmacy Programs (CCAPP-1) has accredited King Faisal University College of Clinical Pharmacy Pharm D program. The National Commission for Academic Accreditation and Assessment (NCAAA) has accredited four undergraduate pharmacy programs: Riyadh Elm University (conditional accreditation of Bachelor of Pharmacy program), Qassim University (full accreditation of Pharm D program) and King Faisal University College of Clinical Pharmacy (Pharm D), King Saud University (Conditional accreditation of Pharm D program), King Saud bin Abdulaziz University for Health Sciences (full accreditation of Pharm D program). ${ }^{25,26}$ The Saudi Pharmacist Licensure Examination (SPLE) was first made mandatory in 2019. SCFHS, which is the agency responsible for the licensures and postgraduate training for healthcare disciplines, has made the exam compulsory for all pharmacy graduates (PharmD and Bachelor's degree students) who wish to practice pharmacy or to pursue a postgraduate training program at the SCFHS. The exam assesses graduates' competencies and readiness to practice pharmacy. ${ }^{27}$ Several postgraduate residency training programs are offered by SCFHS, including PGY1 and PGY2 programs. PGY 2 are offered in the following specialties: Drug Information, Parenteral Nutrition, Cardiology, Critical Care, Internal Medicine, Nephrology, Infectious Disease, Pediatrics, Solid Organ Transplant, Ambulatory Care, and Hematology/Oncology. All are accredited by SCFHS. In 2019, the total number of American Society of health-System Pharmacists (ASHP) accredited PGY 1 programs reached 5 with one in candidate status, while PGY 2 has 3 programs in the following specialties-Solid Organ Transplant, Cardiology, Oncology and two are being evaluated ie, Critical Care and Medication Use Safety and Policy. ${ }^{9}$

\section{Cluster 2: Professional Development DG 4- Advanced and Specialist Development}

There are well-structured education and training facilities in Saudi Arabia for the identified pharmacy workforce development needs for advancing healthcare and health system deliverables. After obtaining an entry-level degree in pharmacy, licensed pharmacists can pursue a clinical pharmacy career pathway by attending the national SCFHS postgraduate residency training. This program was adapted from the US model Postgraduate Year one (PGY1) residency program, with the exception that the Saudi program is 24 months long. ${ }^{9}$ The first 12 months provide a general clinical pharmacy experience by exposing students to inpatient and outpatient pharmacy environments, along with drug information and management. The second 12 months is comprised of six mandatory and three elective 5-week clinical rotations. Specialization in certain areas of clinical pharmacy can be achieved after completion of PGY1 by joining a 12month long PGY2 program. The following specialties are currently offered by the SCFHS: Ambulatory Care, Hematology/Oncology, Cardiology, Drug information, Critical Care, Internal Medicine, Infectious disease, Nephrology, Parenteral nutrition, Pediatrics, Solid Organ Transplant. Another clinical pharmacy career pathway available nationally is the 2.5 -year M.Sc. in clinical pharmacy offered by King Saud University. The program is structured to cover the didactic portion of the curriculum in the first year-and-a-half, while the remaining year is used to complete the clinical experience and a research project. ${ }^{28}$ Specializations in areas other than clinical pharmacy are also available nationally through a wide range of M.Sc. courses offered by various pharmacy colleges and the Ph.D. programs at King Saud University. ${ }^{28}$ Specializations in clinical pharmacy and other pharmaceutical sciences can be achieved through a structured scholarship program that was established by the Ministry of Education to fulfil the 2030 Vision. ${ }^{29}$ Teaching staff at Saudi universities are also offered the opportunity to pursue further education or a specialization at recognized universities outside the Kingdom. According to the SCFHS, specialized pharmacists number 769 , which is 
only $2.6 \%$ of the total pharmacy workforce. Additionally, 796 licensed pharmacists are currently enrolled in a national or international postgraduate pharmacy program. $^{7}$

\section{DG 5- Competency Development}

At the time of this study, no comprehensive competency framework was available for pharmacists in Saudi Arabia, although a published article highlighted the importance of having a competency framework for this group. The basic guide that was developed highlighted the areas of practice that need to be known by a pharmacist holding the initial degree in pharmacy. ${ }^{30}$ The NCAAA issued a set of program learning outcomes as a requirement for accrediting the PharmD programs nationally; these include knowledge, skills, and competencies (autonomy and responsibility, practice, and attribute). ${ }^{26}$ At the national level, however, no official framework is recognized by the regulatory bodies in the different pharmacy sectors.

\section{DG 6- Leadership Development}

Strategies and programmes aiming to developing professional leadership skills are lacking at all stages ie, pharmaceutical sciences and entry level education and training. The lack of a Saudi competency framework for pharmacists results in a lack of strategic programs that focus on developing the specific skills that are core competencies for pharmacists in other nations, such as leadership. For example, The National Competency Standard Framework for Pharmacists in Australia The National Competency Standards Framework for Pharmacists in Australia has a domain for leadership and management to equip pharmacists with the skills needed for working in different professional sectors and settings. ${ }^{31}$ Another example is the Leadership Competency Framework for Pharmacy Professionals offered by the Royal Pharmaceutical Society in the United Kingdom. ${ }^{32}$ The Pharmaceutical Society in Ireland also listed leadership as a core competency under the personal skills section of their framework. ${ }^{33}$

\section{DG 7- Advancing Integrated Services}

A patient-focused and integrated health services essentials for pharmacists advancement that are tailored to social determinants of health are not widely available. Education and training for healthcare providers is monitored by the SCFHS. ${ }^{34}$ The commission strives to provide high quality continuous professional development for all healthcare practitioners, including pharmacists. ${ }^{35}$ The areas that the SCFHS
eLearning Platform offers include communication skills, patient safety, infection and prevention control, and code of ethics. The SCFHS also provides accreditation for the organizations that are Continuous Professional Development (CPD) providers. These providers could be a university, hospital, commission, administrative body, medical association, or an e-platform. The CDP programs may target certain healthcare practitioners such as physicians, dentists, nurses, pharmacists, applied medical specialties, or technicians, or all of them. No specifications limit the focus areas of the programs provided. Several electronic CPD courses have been accredited by the SCFHS with topics such as "credit hours," "virtual medical academy," "mdbriefcase" and "MedEx". ${ }^{35}$

\section{DG 8- Working with Others}

There are no clearly identified component of team-work and interprofessional education and training which are core elements of pharmacists upskilling courses and strategies. Working collaboratively in healthcare, as stated in the definition of WDG- 8 , begins at the education and training stage. ${ }^{4}$ Inter-professional education (IPE) is defined by the UK Centre for the Advancement of Interprofessional Education (CAIPE)“ as an occasion in which two or more professionals learn from and about one another to improve collaboration and the quality of care"; their definition includes members of the professions both before and after qualification, IPE was found to enhance collaboration and competencies among healthcare practitioners with the result of providing highquality health services. Achieving better health outcomes through collaboration among healthcare providers was listed as the first priority in the 2030 Saudi Healthcare Vision. However, according to a study by Fallatah, none of the health science colleges in Saudi Arabia have implemented structured IPE strategies in their curricula in accordance with its classical definition. ${ }^{36}$ Several national studies conducted among healthcare students, including pharmacy, concluded that IPE is important and would improve interaction and communication, thus resulting in positive patient health outcomes. ${ }^{37-39}$

\section{Cluster 3- Systems}

\section{DG 9- Continuing Professional Development} Strategies

Continuous professional development activities are required for re-registration and are accessible. However, they are not guided by learning needs of pharmacists 
working in various settings. Re-registration to continue practicing as a pharmacist is regulated by the SCFHS. The CME requirement is 20 hours per year minimum for a pharmacist's reregistration, 40 hours total. These CME hours are divided into two categories; the first requires a maximum of 25 hours of attending conferences, seminars, workshops, and training courses, as well as writing books, publishing scientific papers and conducting research. The second category, which requires a maximum of 15 hours, includes internal activities, approved internet activities, panel discussions, and general workshops. ${ }^{35}$

\section{DG I0- Equity and Equality}

There are currently some strategies for tackling gender and diversity inequalities in pharmacy workforce development, continuing education and training, and career advancement. According to the SCFHS, the total number of registered pharmacists in Saudi Arabia reached 29,090 in 2018, of which 8273 are Saudi. As stated in the 2018 Ministry of Health Statistical Yearbook, the number of employed pharmacists is 29,125 , of which $24.3 \%$ are Saudi; this compares to $28,312\left(22.2 \%\right.$ Saudi) in $2017 .^{6}$ The ratio of pharmacists was 8.9 per 10,000 population. The data indicate 3953 female pharmacists, comprising $13.5 \%$ of the total workforce; this percentage shows a slight increase compared to the $12.8 \%$ in 2016 . The private sector (hospitals, dispensaries, and community pharmacies) is still the major employer for the pharmacy workforce $(22,467$, $77.1 \%$ ), with community pharmacies employing the largest percentage of pharmacists $(16,685, \quad 57.28 \%)$. However, of the pharmacists working in community pharmacies, only $112(0.38 \%)$ are females. The most recent data (2018) on graduates from the government pharmacy colleges indicates the number of female graduates was $928,(52.2 \%)$, slightly higher than their male counterparts (848). ${ }^{1}$

\section{DG II- Impact and Outcomes}

There is no clear evidence of the effects of the pharmacy workforce interventions within healthcare organizations and health related outcomes. A number of studies have evaluated the impact pharmacists on health outcomes. National level studies showed that pharmacists play an important role on the healthcare team. ${ }^{40}$ Studies also revealed that pharmacists performed a major role in detecting and preventing prescribing errors and medication errors, increasing patient compliance with treatment, performing medication reconciliation, providing patient counselling and playing a key role in raising public health awareness. ${ }^{41-43}$

\section{DG I2- Pharmacy Intelligence}

At a national level there is a plan and corresponding activities to gather and distribute manpower data and manpower planning actions. Health workforce data is managed and regulated by SCFHS and $\mathrm{MOH}$. The $\mathrm{MOH}$ is the authority that monitors healthcare manpower. Annually, it publishes key health indicators related to the pharmacy manpower, including the number of pharmacy colleges, rate of pharmacists per 10,000 population, number of pharmacists in $\mathrm{MOH}$, number of pharmacists in other governmental sectors, number of pharmacists in the private division and the percentage of Saudi employees in each sector. ${ }^{44}$ A more detailed Health Statistics Yearbook is published annually by $\mathrm{MOH}$, indicating the number of pharmacy facilities in the government and private sectors, ie, primary healthcare centers, hospitals, community pharmacies, and dispensaries; the number and distribution of pharmacy employees by region; and the nationality and gender of employees. Data related to pharmacy education includes the number of governmentaffiliated pharmacy colleges, the number of student pharmacists and the number of graduates by gender and nationality. It also monitors the changes in the pharmacy workforce by providing comparisons with the previous year's data, focusing on the nationalization of the profession. ${ }^{6}$ SCFHS also published two reports on the healthcare workforce, including pharmacy. Their data includes the number of pharmacy colleges, both government and private, the number of student pharmacists enrolled in undergraduate pharmacy programs in Saudi Arabia by nationality, the number of students studying abroad, and the number of pharmacy students enrolled in national and international postgraduate pharmacy programs. Additionally, this report contains the number of licensed pharmacists, unemployed pharmacists, and specialized pharmacists by nationality. It also provides a 10-year projection of the pharmacy profession. ${ }^{1,7}$

\section{DG I3- Policy Development}

There are focused and feasible techniques to implement full needs-based advancement of the pharmacy workforce from early education through to higher level of practice. The pharmacy profession is regulated by the $\mathrm{MOH}$, the SCFHS, and the Ministry of Human Resources and Social Development (HRSD). Based on the statistical data that monitors pharmacy human resources, the related assumptions, and the recommendations published by both $\mathrm{MOH}$ 
and SCFHS, the HRSD issues policies that regulate the profession. ${ }^{6,7}$ A recent policy suggested gradually nationalizing the profession to $20 \%$ by 2020 and $30 \%$ by 2021 . In addition, a policy was also put into place to ease the restrictions that previously limited number of women working in community pharmacies. ${ }^{45}$

\section{Mapping to the FIP DGs Workforce Element}

The categorization DG of Academia (3 items), Professional Development (5 items), and Systems (5 items). Categorization of the cluster was based on the categorization of the DGs of that cluster. Academia cluster met the FIP DG standards, Professional Development failed to meet the FIP DG standards. Systems cluster partially met the FIP DG standards. The overall DG (13 items), pharmacy workforce in Saudi Arabia, partially met the FIP DG standards. Refer to Table 1 and Figure 1.

\section{Discussion}

This study used the FIP DGs as a guide to improve pharmaceutical workforce education, professional development, and policy making. ${ }^{4}$ The 13 DGs were classified into 3 Clusters: Academia, Professional Development, and Systems. ${ }^{4}$ The findings note that Cluster 1 of the DGs, Academia, is relatively well established. This case study on Saudi Arabia revealed the success of the sustainable efforts that education policy makers have made to transform pharmacy education in the country. The focus was initially directed toward increasing the number of qualified Saudi pharmacy employees. ${ }^{1}$ This was successfully achieved by increasing the number of pharmacy education institutions from 1 in 2006 to 30 in 2020 (DG 1). ${ }^{9}$ The focus was then gradually shifted to assure that the quality of education met national and international standards. ${ }^{24} \mathrm{~A}$ few pharmacy colleges around the country have obtained international accreditation/ certification from reputable quality assurance organizations such as the ACPE and CCAPP. ${ }^{24}$ Nationally, the NCAAA was established in 2004 and started accrediting programs in 2010; hence, pharmacy colleges began to seek national accreditation and a few have obtained it (DG 2). ${ }^{25,26}$ As sustainable production of a Saudi pharmaceutical workforce was assured, more attention was diverted towards foundation training and early career development. Several postgraduate pharmacy programs (Master's and Ph.D.) were established in pharmacy colleges around the country. ${ }^{7}$ Clinical pharmacy residency programs also expanded to cover various specialties and these were made accessible to the geographically scattered pharmaceutical workforce by accrediting health care centers in different regions of Saudi Arabia (DG 3). ${ }^{22}$ This study argues that Cluster 1 of the WDGs, Academia, has basically been achieved. On the other hand, Cluster 2, Professional Development, is not as well developed. Despite the efforts made by pharmacy regulatory bodies, especially the SCFHS, to advance healthcare specialties, some DGs are still not defined. In other words, Advanced and Specialist Development (DG 4) and Advancing

\begin{tabular}{|c|c|c|c|c|c|c|}
\hline Category & \multicolumn{6}{|c|}{ Development Goals } \\
\hline Met & $\begin{array}{c}\mathbf{1} \mid \boldsymbol{Q} \\
\text { ACADEMC } \\
\text { CAPACITY }\end{array}$ & $2 \mid \Theta$ & 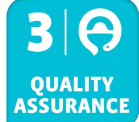 & $4 \mid \mathcal{A}$ & 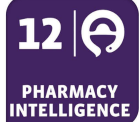 & $\begin{array}{c}13 \mid \\
\substack{\text { ponct } \\
\text { over }}\end{array}$ \\
\hline Partially met & 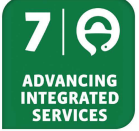 & 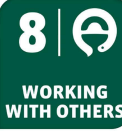 & 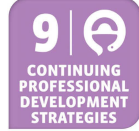 & $\begin{array}{l}10 \mid \curvearrowright \\
\text { EQUUTY } \\
\text { EQUALITY }\end{array}$ & & \\
\hline $\begin{array}{l}\text { Failed to } \\
\text { meet }\end{array}$ & 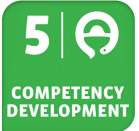 & 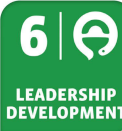 & $\begin{array}{l}11 \mid \Theta \\
\text { impecte } \\
\text { ovitomes }\end{array}$ & & & \\
\hline
\end{tabular}

Figure I Mapping the current status of the national pharmaceutical workforce to FIP DGs.

Notes: Reproduced with permission from the International Pharmaceutical Federation (FIP). The FIP Development Goals: Transforming global pharmacy. The Hague: International Pharmaceutical Federation; 2020. Available from: https://www.fip.org/file/4793..$^{5}$ ○ Copyright 2020 International Pharmaceutical Federation (FIP). 
Integrated Services (DG 7) were considerably fulfilled by having general and specialized advanced pharmacy programs, such as PGY1 and PGY2, and having CPD programs offered by the SCFHS and other recognized CPD providers. ${ }^{9}$ However, the lack of a national competency framework for pharmacists (DG 5) make the required skills, attitudes and values ambiguous. Unfortunately, Leadership Development (DG 6), which is a core competency in some international competency frameworks, has not yet been identified as an important aspect of workforce professional development here. ${ }^{32,33}$ Working with Others (WDG 8), a concept that refers to inter-professional education, is recognized and valued but has not been implemented. ${ }^{36}$ Hence, Cluster 2 of the DGs seems to be the most lacking of the goals. For the past few years, attention to Cluster 3, Systems, goals has been given to DGs 10,12 , and 13- equity and equality, pharmacy intelligence, and policy development. Policies monitoring the pharmaceutical workforce have been formed and implemented in response to changes in Cluster 1, Academia, the supply side of the workforce. ${ }^{1} \mathrm{MOH}$ is the authority that publishes reports regarding the health care workforce, including pharmacy. However, this data had not impacted policy formation until the SCFHS joined $\mathrm{MOH}$ in publishing health care workforce data. ${ }^{6,7}$ Additionally, the Saudi Vision 2030 also outlined some goals related to healthcare and, hence, guided some changes in regulations related to the pharmaceutical workforce. ${ }^{2,46}$ One example is the increase in the employment of female pharmacists in community pharmacies due to easing the restrictions that prevented women from working in the largest employment sector. However, despite the efforts being made, the numbers indicate that gender imbalance is still an issue in the pharmacy workforce, with females being under-represented in the profession. ${ }^{6}$ Another example is the recent policy issued by the HRSD to force the private sector, including community pharmacy, to gradually renationalise the profession in two stages, $20 \%$ by 2020 and $30 \%$ by 2021 . The country, however, has been slow to achieve Saudisation of the profession by increasing the proportion of Saudi pharmacists. ${ }^{45}$ Regarding the Continuing Professional Development Strategies (DG9), although a certain number of $\mathrm{CME}$ hours are required for re-registration as a pharmacist, these CME hours are not linked to a needsbased health initiative. This could be the result of the lack of a national competency framework that guides needsbased professional development activities. ${ }^{35}$ In terms of Impact and Outcomes (DG 11), the profession has so far only documented the effects of the pharmacy manpower in the form of published journal articles, while official evidence of the impact of pharmacists within health systems and toward health related outcomes is not available.Efforts made by pharmacy stakeholders in different sectors should be directed towards advancement of professional development cluster, in particular developing a competency framework for pharmacists. Having a national competency framework would facilitate in the advancement of unfulfilled Dgs such as leadership development and working with others. Another identified priority is impact and outcome, better documentation of pharmacy workforce impact within health system and health outcomes.

\section{Limitations}

This study covered only 13 of the 21 FIP DGs since this is the first country-level overview appraising needs assessment, prioritization and implementation of the action plan designed specifically for the Kingdom of Saudi Arabia. Future work will focus on the remaining 8 DGs.

\section{Conclusion}

This study used the FIP WDGs framework to provide insights into the systemic needs of the pharmacy workforce in Saudi Arabia. The identified strategic priorities included the need for a national competency framework to guide other development goals, such as leadership development, CDP strategies, working with others, and national data on impacts and outcomes. This research provides a guide for the advancement of the pharmacy profession in Saudi Arabia, which will, in turn, direct the efforts of education stakeholders, decision makers, and regulatory authorities to overcome the shortcomings identified in their respective areas and to fulfil the Saudi 2030 Healthcare Vision.

\section{Ethical Approval}

Ethical clearance was given by the Ethical Committee of the Scientific Research, King Khalid University ECM\#2021-5313.

\section{Funding}

This study did not receive any grant from funding agencies.

\section{Disclosure}

The authors report no conflicts of interest for this work. 


\section{References}

1. Almaghaslah D, Alsayari A, Asiri R, Albugami N. Pharmacy workforce in Saudi Arabia: challenges and opportunities: a Cross-Sectional Study. Int J Health Plann Manage. 2018;34(1). doi:10.1002/hpm.2674

2. Saudi 2030 vision. 2030 vision; 2016. Available from: https:// vision2030.gov.sa/en. Accessed February 30, 2020.

3. Al-Haqan A, Smith F, Al-Taweel D, Bader L, Bates I. Using a global systematic framework tool to guide the advancement of the pharmacy workforce education and training on a national level. Res Soc Adm Pharm. 2021;17(6):1101-1109. doi:10.1016/j.sapharm.2020.08.008

4. International Pharmaceutical Federation. Pharmaceutical workforce development goals; transforming global pharmacy. The Hague, The Netherlands: FIP; 2016. Available from: https://www.fip.org/www/ strea mfile.php filename=fip/PharmacyEducation/2016_report/201611-Education-wo rkforce-development-goals.pdf. Accessed June 30, 2020.

5. International Pharmaceutical Federation. Pharmaceutical workforce development goals; transforming global pharmacy. The Hague, The Netherlands: FIP; 2020. Available from: https://www.fip.org/file/ 4793. Accessed June 30, 2020.

6. Ministry of Health. Statistical Yearbook. Riyadh, Saudi Arabia: Ministry of Health. Available from:: https://www.moh.gov.sa/en/ Ministry/Statistics/book/Pages/default.aspx. Accessed May 30, 2020.

7. Saudi Commission for Health Specialties. Facts about health workforce for 10 years: 2018-2027. Riyadh, Saudi Arabia: Ministry of Health. Available from: https://www.scfhs.org.sa/Media/ DigitalLibrary/DocumentLibrary/OtherPublications/Documents/1\% D9\%88\%D8\%A7\%D9\%82\%D8\%B9_\%D8\%A7\%D9\%84\%D9\% 82\%D9\%88\%D9\%89_\%D8\%A7\%D9\%84\%D8\%B9\%D8\%A7\% D9\%85\%D9\%84\%D8\%A9_\%D8\%A7\%D9\%84\%D8\%B5\%D8\%AD \%D9\%8A\%D8\%A9.pdf. Accessed May 30, 2020.

8. Meilianti S, Smith F, Ernawati D, Pratita R, Bates I. A country-level national needs assessment of the Indonesian pharmacy workforce. Res Soc Adm Pharm. 2021. doi:10.1016/j.sapharm.2021.03.003

9. Badreldin H, Alosaimy S, Al-jedai A. Clinical pharmacy practice in Saudi Arabia: historical evolution and future perspective. $J$ Am Coll Clin Pharm. 2020. doi:10.1002/jac5.1239

10. Cheema E. The need to introduce simulation-based teaching in pharmacy education in Saudi Arabia. Pharmacy. 2018;6(3):60. doi:10.3390/pharmacy6030060

11. Almaghaslah D, Alsayari A, Almodeer L, et al. A qualitative study exploring pharmacy education in a Saudi pharmacy school running two entry-level pharmacy programmes. Pharm Educ. 2019;19:93-99.

12. Aljadhey H. Experience and future of introductory pharmacy practice training in developing countries: example of Saudi Arabia. Am J Pharm Educ. 2012;76(10):205. doi:10.5688/ajpe7610205

13. Aljadhey H. Challenges facing advanced pharmacy practice experience in Saudi Arabia. Am J Pharm Educ. 2013;77(1):19. doi:10.5688/ ajpe 77119

14. Al-jedai A, Qaisi S, Al-meman A. Pharmacy practice and the health care system in Saudi Arabia. Can J Hosp Pharm. 2016;69(3). doi:10.4212/cjhp.v69i3.1561

15. King Saud University. Postgraduate Programs. 2021. Available from: https://pharmacy.ksu.edu.sa/ar/postgraduate-programs.acessed. Accessed May 30, 2020.

16. Umm Al-Qura University. Postgraduate Programs. 2021.Available from: https://uqu.edu.sa/pharmcol/1485. Accessed April 3, 2020.

17. Prince Sattam bin Abdulaziz University. Master Program. 2021. Available from: https://pharmacy.psau.edu.sa/en/psau/acedemicpro gram/62/2559/5. Accessed July 26, 2021.

18. King Faisal University. Postgraduate Programs. Available from: https://mportal.kfu.edu.sa/ar/Deans/HigherStudies/Pages/PGSPrograms.aspx. Accessed April 3, 2020.
19. Jazan University. M.S. in Applied Toxicology in Pharmaceutical Sciences. 2021. Available from: https://www.jazanu.edu.sa/phar/ m-s-in-applied-toxicology/. Accessed July 26, 2021.

20. Qassim University; 2021. Master Programs. Available from: https:// pharmacy.qu.edu.sa/. Accessed April 3, 2020. Arabic.

21. King Abdelaziz University. Postgraduate Programs. 2021. Available from: https://pharmacy.kau.edu.sa/ViewGraduates.aspx?Site_id=166. Accessed April 182021.

22. Saudi Commission for Health Specialties. Clinical pharmacy residency programs. 2017. Available from: https://www.scfhs.org.sa/en/ MESPS/TrainingProgs/List\%20graduate\%20programs/Documents/ Clinical\%20Pharmacy.pdf. Accessed April 3, 2020.

23. Saudi Commission for Health Specialties. Guidelines of professional classification and registration for health practitioners. 2014. Available from: https://www.scfhs.org.sa/en/registration/ClassAndRegister/ Reregister/Documents/Professional\%20Classification\%20manual\% 20for\%20Health\%20Practitioners.pdf. Accessed April 3, 2020.

24. Accreditation council for pharmacy education. Saudi Arabia. 2021. Available from: https://www.acpe-accredit.org/faqitem/saudi-arabia/. Accessed: December 13, 2020.

25. The National Center for Academic Accreditation and Evaluation. Accredited Programs; 2021. Available from: https://etec.gov.sa/ar/ productsandservices/NCA A A/academic/Pages/ ProgramsDirectoryaspx. Accessed April 13, 2021.

26. Alkhateeb F, Arkle S, McDonough S, Latif D. Review of national and international accreditation of pharmacy programs in the gulf cooperation council countries. Am J Pharm Educ. 2018;82(10):5980. doi: $10.5688 /$ ajpe 5980

27. Saudi Commission for Health Specialties. Saudi Pharmacist Licensure Examination (SPLE). 2019. Available from: https://www. scfhs.org.sa/examinations/TrainingExams/OverallEntranceExam/ Documents/SPLE\%20Applicant\%20Guide.pdf. Accessed April 3, 2020.

28. The Pharmaceutical Society of Ireland. Core Competency Framework For Pharmacists. 2013. Available from: https://www.thepsi.ie/ Libraries/Pharmacy_Practice/PSI_Core_Comp_Framework_Web_ Version_Final.sflb.ashx. Accessed April 3, 2020.

29. King Saud University. Deanship of Graduate Studies. 2020. Available from:https://graduatestudies.ksu.edu.sa/en/node/933. Accessed April 3, 2020.

30. Ministry of Education. Safeer. 2021. Available from: https://www. moe.gov.sa/en/aboutus/nationaltransformation/Pages/employment strategy.aspx. Accessed April 3, 2021.

31. Alomi Y. National pharmacist competency system at ministry of health hospitals in Saudi Arabia. J Pharmacol Clin Res. 2016;1 (3):548. doi:10.19080/jpcr.2016.01.555563

32. Pharmaceutical Society of Australia. National competency standards framework for pharmacists in Australia. 2016. Available from: https://www.psa.org.au/wp-content/uploads/2018/06/NationalCompetency-Standards-Framework-for-Pharmacists-in-Australia -2016-PDF-2mb.pdf. Accessed April 3, 2021.

33. Royal Pharmaceutical Society. Leadership Competency Framework for Pharmacy Professionals. 2010. Available from: https://www.net works.nhs.uk/nhs-networks/healthcare-professionals-commissioningnetwork/meeting-notes/6-september-2011/Leadership\%20compe tency $\% 20$ Framework $\% 20$ for $\% 20$ pharmacy $\% 20$ professionals $\% 20-\%$ 20Liz.pdf. Accessed April 3, 2021.

34. The Pharmaceutical Society of Ireland. National competency framework for pharmacists working in cancer care. 2013. Available from: https://www.hse.ie/eng/services/list/5/cancer/profinfo/training/pharma cist $\% 20$ cancer $\% 20$ care $\% 20$ competency $\% 20$ frameword.pdf. Accessed April 3, 2021.

35. AlRuthia Y, Alsenaidy M, Alrabiah H, AlMuhaisen A, Alshehri M. The status of licensed pharmacy workforce in Saudi Arabia: a 2030 economic vision perspective. Hum Resour Health. 2018;16(1). doi:10.1186/s12960-018-0294-8 
36. Fallatah H. Introducing inter-professional education in curricula of Saudi health science schools: an educational projection of Saudi Vision 2030. J Taibah Univ Med Sci. 2016;11(6):520-525. doi:10.1016/j.jtumed.2016.10.008

37. Al-Eisa E, Alderaa A, AlSayyad A, et al. The perceptions and readiness toward interprofessional education among female undergraduate health-care students at King Saud University. J Phys Ther Sci. 2016;28(4):1142-1146. doi:10.1589/jpts.28.1142

38. Zamil H, Meo S. Medical students' readiness and perceptions about Interprofessional Education: a cross sectional study. Pak J Med Sci. 2020;36(4). doi:10.12669/pjms.36.4.2214

39. AlAhmari MD. Interprofessional education: Saudi health students' attitudes toward shared learning. Adv Med Educ Pract. 2019;10:1061-1067. doi:10.2147/AMEP.S226477

40. Kabel AM, Bakr MM, Alshanbari AM, et al. Perceptions and attitudes towards clinical pharmacy services and their impact on the management of cancer in Taif, Saudi Arabia. Asian Pac J Cancer Prev. $\quad$ 2020;21(2):531-538. doi:10.31557/APJCP.2020.21.2.531 PMID: 32102535 ; PMCID: PMC7332119.

41. Al-Dhawailie AA. Inpatient prescribing errors and pharmacist intervention at a teaching hospital in Saudi Arabia. Saudi Pharm J. 2011;19(3):193-196. PMID: 23960759; PMCID: PMC3745085. doi:10.1016/j.jsps.2011.03.001

42. Abdulghani KH, Aseeri MA, Mahmoud A, Abulezz R. The impact of pharmacist-led medication reconciliation during admission at tertiary care hospital. Int $J$ Clin Pharm. 2018;40(1):196-201. PMID: 29248986. doi:10.1007/s11096-017-0568-6
43. Alaqeel S, Abanmy NO. Counselling practices in community pharmacies in Riyadh, Saudi Arabia: a cross-sectional study. BMC Health Serv Res. 2015;15:557. doi:10.1186/s12913-015-1220-6. PMID: 26669857 ; PMCID: PMC4678714.

44. MOH. Key Health Indicators; 2020. Available from: https://www. moh.gov.sa/en/Ministry/Statistics/Indicator/Pages/default.aspx. Accessed: 13 December 2020.

45. Human Resources And Social Development. [Renationalisation of the pharmacy profession]; 2020. Available from: https:/hrsd.gov.sa/ sites/default/files/\%D8\%A7\%D9\%84\%D8\%AF\%D9\%84\%D9\%8A \%D9\%84\%20\%D8\%A7\%D9\%84\%D8\%A3\%D8\%AC\%D8\%B1\% D8\%A7\%D8\%A6\%D9\%8A\%20\%D9\%84\%D8\%AA\%D9\%88\% D8\%B7\%D9\%8A\%D9\%86\%20\%D9\%85\%D9\%87\%D9\%86\%D8\% A $9 \% 20 \%$ D $8 \%$ A 7\%D $\% 84 \% D 8 \% B 5 \% D 9 \% 8 A \% D 8 \% A F \% D 9 \%$ 84\%D8\%A9.pdf. Accessed July 26, 2021. Arabic.

46. Almaghaslah D, Alsayari A, Almanasef M, Asiri A. A cross-sectional study on pharmacy students' career choices in the light of Saudi vision 2030: will community pharmacy continue to be the most promising, but least preferred, sector? Int J Environ Res Public Health. 2021;18:4589. doi:10.3390/ijerph18094589
Risk Management and Healthcare Policy

\section{Publish your work in this journal}

Risk Management and Healthcare Policy is an international, peerreviewed, open access journal focusing on all aspects of public health, policy, and preventative measures to promote good health and improve morbidity and mortality in the population. The journal welcomes submitted papers covering original research, basic science, clinical \& epidemiological studies, reviews and evaluations,

\section{Dovepress}

guidelines, expert opinion and commentary, case reports and extended reports. The manuscript management system is completely online and includes a very quick and fair peer-review system, which is all easy to use. Visit http://www.dovepress.com/testimonials.php to read real quotes from published authors. 